\title{
Avaliação da gestão de resíduos da construção civil em Cuiabá e Várzea Grande
}

\section{Waste construction management evaluation in Cuiabá and Várzea Grande}

Data de entrada: 20/10/2014

Data de aprovação: 05/09/2016

\section{Resumo}

Este trabalho visa a avaliar a gestão dos resíduos da construção civil nos municípios de Cuiabá e Várzea Grande, em termos qualiquantitativos, bem como apresentar recomendações para o aperfeiçoamento da gestão de resíduos. Para avaliar os resíduos da construção civil, elegeram-se as obras de engenharia civil, oriundas de proponentes públicos e privados, localizadas dentro do perímetro urbano de Cuiabá e Várzea Grande, na modalidade de novas construções em andamento, no período de junho de 2012 a junho de 2013, no setor de habitação. Diante das obras investigadas e cálculos estatísticos, Cuiabá apresenta geração estimada de resíduos da construção civil de $1.085 .500 \mathrm{~kg}$ por dia e, para novas construções em andamento, no setor de habitação, com áreas acima de $12.000 \mathrm{~m}^{2}$, $130.850 \mathrm{~kg}$ por dia, contra $609.500 \mathrm{~kg}$ por dia e $72.770 \mathrm{~kg}$ por dia, respectivamente, em Várzea Grande. Palavras-chave: Novas construções. Habitação. Gestão de resíduos.

\section{Abstract}

The proposed is to evaluate the waste construction management in Cuiabá and Várzea Grande, through qualitative and quantitative terms, as well offer recommendations for improving the waste management. To evaluate waste construction, it was elected civil engineering construction, from public and private sector, located within the cities of Cuiabá and Várzea Grande, new ongoing constructions type, from June/2012 to June/2013, of dwelling sector. Through the constructions studied and statistics calculation, waste construction estimated in Cuiabá is $1.085 .500 \mathrm{~kg}$ daily and, for new constructions in progress, of dwelling sector, more than $12.000 \mathrm{~m}^{2}$, is $130.850 \mathrm{~kg}$, versus $609.500 \mathrm{~kg}$ daily and $72.770 \mathrm{~kg}$ daily, respectively, in Várzea Grande. Keywords: New constructions. Dwelling sector. Waste construction management.

Marcello Victor Monteiro Dondo - Mestre de Engenharia de Edificações e Ambiental, especialista em Engenharia de Segurança do Trabalho e bacharel em Engenharia Sanitária e Ambiental. Perito criminal oficial da Perícia Oficial e Identificação Técnica de Mato Grosso (Politec-MT). Endereço para correspondência: Av. A, Condomínio Monte Carlo, Torre 5, Apartamento 25, Jd. Florianópolis, Loteamento Parque das Nações, CEP: 78055-799, Cuiabá-MT; 065 9998 3849; marcellomonteiroabrturbo.com.br 


\section{INTRODUÇÃO}

Nos termos da Política Nacional de Resíduos Sólidos (PNRS) - Lei no 12.305/2010 - e da Resolução CONAMA n 307/2002, os Resíduos da Construção Civil (RCC) são aqueles gerados nas construções, reformas, ampliações e reparos de obras de construção civil, incluídos os resultantes da preparação e escavação de terrenos para obras civis que são de responsabilidade do gerador, transportador, receptor e beneficiador.

Segundo o Ministério do Meio Ambiente (MMA, 2010), estima-se que, em âmbito nacional, as obras de construção civil, em sua maioria, continuam a utilizar modelos construtivos tradicionais, atingindo $95 \%$ do total (tijolos, argamassa, concreto, areia, brita, pedra, cimento, telhas cerâmicas, tubulações de policloreto de vinila, cabos elétricos de cobre, tintas, resinas, adesivos, cola, silicones, óleos ou fluidos impermeabilizantes, entre outros), sendo que a composição média dos RCC no Brasil alcança 92\% de argamassa, concreto, tijolos e blocos cerâmicos.

Nesses mesmos modelos construtivos de obras e contexto (MMA, 2010), geram-se quantias volumosas de RCC, na ordem de $500 \mathrm{~kg} /$ habitante ano e 31.000 .000 t/ano, o que pode representar, aproximadamente, 70\% do total de Resíduos Sólidos Urbanos (RSU) gerados, além de as perdas por quebras ou avarias de materiais intracanteiros de obras atingirem, em média, índices de $20 \%$ na composição do total de RCC gerados.

No cenário brasileiro, estima-se que, a cada metro quadrado de construção executada de um edifício qualquer, é requerida, aproximadamente, uma tonelada de matéria-prima (recursos naturais); as contribuições das construções formais (com alvarás e licença ambiental) participam com índice de até $30 \%$ do total de resíduos gerados, sendo os $70 \%$ restantes oriundos das construções informais (sem licença ambiental). Em contrapartida, as perdas sempre ocorrem, mesmo que se melho- re o processo produtivo de construção; por exemplo, considerando o peso específico/densidade de RCC global de aproximadamente $1.200 \mathrm{~kg} / \mathrm{m}^{3}$ (fator médio de conversão de massa para volume e vice-versa de RCC, sem fator de correção, desconsiderando efeitos de umidade e empolamento), a estimativa média de geração de entulho de obras varia de $120 \mathrm{~kg} / \mathrm{m}^{2}$ a $150 \mathrm{~kg} / \mathrm{m}^{2}$ (SOUZA, 2005).

Para tanto, visando a abordar as nuanças da indústria da construção civil, no que tange aos RCC, elegeram-se as obras de engenharia civil, oriundas de proponentes públicos e privados, localizadas dentro do perímetro urbano, na modalidade de novas construções em andamento, no período de junho de 2012 a junho de 2013, no setor de habitação, nos municípios de Cuiabá e Várzea Grande.

Como hipótese da pesquisa, tem-se a implantação voluntária do Plano de Gerenciamento de Resíduos de Construção Civil (PGRCC) e da gestão de RCC nos canteiros de obras, no ramo da construção civil, como diferencial de competição entre construtoras e outras do gênero, capaz de contribuir para a minimização dos impactos ambientais negativos, ou apenas cumprindo as exigências legais dos órgãos oficiais competentes.

Portanto, o aprimoramento da gestão de resíduos pode auxiliar indireta e diretamente a fiscalização dos serviços públicos e a aplicabilidade da responsabilidade compartilhada dos geradores e transportadores de resíduos, bem como subsidiar a implantação dos planos de gerenciamento de resíduos nas prefeituras e nos canteiros de obras, com benefícios sociais, econômicos e ambientais nas municipalidades.

\section{OBJETIVOS}

\subsection{Objetivo geral}

Avaliar a gestão de RCC em obras públicas e privadas, no setor de habitação, em Cuiabá e Várzea Grande. 


\subsection{Objetivos específicos}

Realizar caracterização qualiquantitativa dos RCC oriundos de obras do setor de habitação, em Cuiabá e Várzea Grande.

Verificar a capacidade de gestão de RCC nas obras de habitação públicas e privadas de Cuiabá e Várzea Grande.

Apresentar dispositivos administrativos, técnicos, operacionais e legais viáveis à gestão dos RCC nas obras de habitação e prefeituras de Cuiabá e Várzea Grande.

\section{METODOLOGIA}

Considerando que este artigo pretende avaliar a gestão dos RCC nas prefeituras e obras públicas e privadas de habitação de Cuiabá e Várzea Grande, tem-se a seguinte ordem, disposição e organização da estrutura metodológica: (i) a citação e as referências dos locais objetos de estudo; (ii) a seleção e critérios de amostragem; (iii) as considerações preliminares para avaliar a gestão de RCC; (iv) o estabelecimento de critérios para quantificar a geração; (v) a determinação de critérios e adoção de indicadores de avaliação para qualificar a gestão aplicada aos RCC, comparando-os às recomendações técnico-legais da Resolução CONAMA n' 307/2002 e suas alterações, das NBRs 15112 a 15116, da Associação Brasileira de Normas Técnicas (ABNT) (elencados no Anexo A deste artigo).

\subsection{Locais de estudo}

Os locais estudados foram os dois principais municípios do estado de Mato Grosso, com relevantes índices socioeconômicos, Cuiabá (capital) e Várzea Grande (cidade vizinha e que faz limite físico natural pelo rio Cuiabá), localizados na microrregião de Cuiabá, mesorregião Centro-Sul do referido estado, região de planejamento VI/Baixada Cuiabana.

\subsection{Amostragem}

Os locais investigados (população-alvo ou amostras) foram os canteiros de obras de construção civil, por meio de visitas técnicas in loco, considerando obras com 24 meses de prazo máximo de execução (já inclusos os atrasos no cronograma de execução), grandes volumes de RCC (superior a $1 \mathrm{~m}^{3}$ ), exclusos os resíduos volumosos, industriais, especiais e de limpeza pública, unidades edificantes para fins de moradia, população municipal adquirente de imóveis de três a dez salários-mínimos (classe média), área total construída acima de $12.000 \mathrm{~m}^{2}$, modalidade de novas construções em andamento, padrão construtivo tradicional e convencional, na área de habitação (condomínios verticais residenciais multifamiliares com 18 a 20 pavimentos, quatro unidades por pavimento e 72 a 80 unidades no total), no período de junho de 2012 a junho de 2013, dentro dos perímetros urbanos de Cuiabá e Várzea Grande (municípios de grande porte, com mais de 50.000 habitantes).

A amostra nesses locais foi de 20 unidades construtivas, junto a construtoras com razões sociais diferentes entre si, sindicalizadas no Sindicato das Indústrias da Construção do Estado de Mato Grosso (Sinduscon-MT) e legalizadas, com padrão construtivo similar e maior número de obras de habitação em execução no referido período e nos locais objetos de estudo já mencionados. Essa amostra traduz um alcance de $20 \%$ de novas unidades construtivas nos dois municípios (SECOVI, 2013).

No município de Cuiabá, foram 15 unidades visitadas e, em Várzea Grande, cinco, sendo um quinto das unidades visitadas de proponentes privados e quatro quintos de proponentes públicos nos dois municípios. A frequência e periodicidade das visitas técnicas deram-se da seguinte forma: uma por bimestre em cada obra, ou seja, seis em cada obra em um ano, totalizando 120 visitas e um ano de estudo. 
As visitas técnicas às prefeituras foram quatro, sendo duas em Cuiabá e duas em Várzea Grande. A frequência e periodicidade deram-se concomitantemente à fase de visita às obras: uma por mês em cada prefeitura, totalizando quatro visitas.

\subsection{Considerações preliminares para avaliação da gestão de RCC}

A pesquisa baseou-se predominantemente em fontes de informações secundárias, ou seja, artigos técnico-científicos, livros, trabalhos acadêmicos e consulta prévia a órgãos públicos oficiais e entidades particulares afetos à área de gestão ambiental, devido a dificuldades inerentes à consecução de trabalhos acadêmicos dessa natureza.

Foram utilizados, na realização da pesquisa: trena em fibra de nylon, extensão máxima de $30 \mathrm{~m}$, para medição de distâncias entre pontos de geração e armazenamento temporário de resíduos intracanteiros de obras públicas e privadas; máquina fotográfica digital Sony Cyber Shot, para registrar a gestão de RCC nas obras; e maquinário de informática (computador, software Excel, pacote Office, versão 2007), para digitalização dos dados, cálculo de estimativas, médias geométricas e aplicação de estatística descritiva junto às variáveis escalares.

Questionários foram elaborados, com realização de pré-teste e plano de amostragem, para então haver condições de aplicação junto aos canteiros de obras e prefeituras, apresentando as principais respostas dos questionamentos que permitem e contribuem na avaliação da gestão de RCC, classificação dos RCC durante os estágios das obras, caracterização qualitativa das variáveis que influenciam indiretamente a gestão de RCC e comparação da gestão de RCC entre os municípios, fundamentadas nas leis ambientais vigentes, normas técnicas pertinentes e referências bibliográficas. Resumidamente, avaliaram-se a existência, implementação, atualização e manutenção das políticas ambientais, planos e programas volta- das aos RCC, averiguando também a capacidade técnica e operacional do gerenciamento das municipalidades e os canteiros de obras na gestão de RCC.

Os questionários foram compostos por perguntas objetivas, abertas, com variáveis qualiquantitativas, e aplicados por entrevistas estruturadas, em turno diurno (matutino ou vespertino), em dias de semana e no momento de produção das obras e das atividades rotineiras das prefeituras. Já os entrevistados foram os responsáveis técnicos da secretaria competente na área ambiental de RCC nas prefeituras e os engenheiros ou arquitetos seniores nos canteiros de obras.

A aplicação de estatística descritiva também foi adotada junto às respectivas medidas de dispersão e tendências, restringindo-se às duas principais grandezas escalares que influenciam os cálculos estimativos de geração de RCC, no caso particular de Cuiabá e Várzea Grande, e baseando-se nos modelos e adaptações de estimativas apresentados na revisão bibliográfica - número de caçambas estacionárias removidas das obras e geração de RCC. Essa iniciativa teve o intuito de verificar a representatividade da amostragem em comparação com as situações existentes nos locais de estudo acerca da gestão de RCC.

\subsection{Critérios de avaliação adotados para quantificar a geração de RCC nos canteiros de obras}

Para realizar a estimativa de geração de RCC nos canteiros de obras públicas e privadas de Cuiabá e Várzea Grande, com as características construtivas previamente estabelecidas e elencadas, fezse necessária a utilização de método de pesquisa do tipo investigatório e experimental, baseado em grandezas escalares indicadas na revisão bibliográfica (MMA, 2010; MARQUES NETO, 2005; SOUZA, 2005) e adaptações, demais grandezas escalares não abordadas anteriormente, variáveis quantitativas e fatores de correção necessários, 
devido às realidades locais (DONDO, 2007; SECOVI, 2013; SINDUSCON-MT, 2012).

Diante dos critérios aqui adotados e adaptações matemáticas necessárias, demonstram-se e exemplificam-se as referidas variáveis e grandezas escalares minuciosamente para estimativa de perdas de materiais e geração de RCC nos canteiros de obras públicas e privadas de Cuiabá e Várzea Grande, com a descrição das suas respectivas unidades e análises dimensionais, nas Equações 1 , 2, 3, 4 e 5 .

$R=[(T \times N \times G) / H]$

Em que:

$\mathrm{R}$ = estimativa de geração de RCC exclusiva para novas construções, massa gerada por $\mathrm{dia}(\mathrm{kg} / \mathrm{d})$.

T = média geométrica das áreas totais construídas das edificações investigadas públicas e privadas no período de execução total das obras $\left(\mathrm{m}^{2}\right)$.

$\mathrm{N}=$ número de novas edificações em andamento, de junho de 2012 a junho de 2013, com áreas construídas superiores a $12.000 \mathrm{~m}^{2}$ (adimensional).

$\mathrm{G}=$ média geométrica da geração de $\mathrm{RCC}\left(\mathrm{kg} / \mathrm{m}^{2}\right)$.

$\mathrm{H}=$ quantidade de dias de efetivo trabalho e execução de obras com prazo de execução de 24 me$\operatorname{ses}(d)$.

$V=(R \times 0,2)$

Em que:

$V=$ estimativa de perdas por quebra ou avaria de materiais intracanteiros de obras que incorporam os RCC, massa por dia $(\mathrm{kg} / \mathrm{d})$.

$R=$ valor da Equação $1(\mathrm{~kg} / \mathrm{d})$.
0,2 = perda de material por quebra ou avaria intracanteiros de obras média adotada de $20 \%$ em decimal (adimensional).

$S=[(R \times C 1 \times C 2)]$

Em que:

$S$ = estimativa de geração total de RCC municipal $(\mathrm{kg} / \mathrm{d})$.

$R=$ valor da Equação $1(\mathrm{~kg} / \mathrm{d})$.

C1 = coeficiente de correção 1, obtido pela razão entre o total de resíduos gerados no município de Cuiabá de novas construções e o total de resíduos gerados nas obras do município de novas construções com áreas menores que $12.000 \mathrm{~m}^{2}$, dos condomínios horizontais, da zona rural, das reformas, ampliações, demolições e revitalizações e das em situação paralisada e finalizada (adimensional).

C2 = coeficiente de correção 2 , obtido pela razão entre o total de resíduos gerados no município de Cuiabá pelo setor de habitação e de resíduos gerados pelos demais setores (lazer, educação, saúde, entre outros), com exceção das obras de mobilidade urbana e transporte na malha viária terrestre (adimensional).

$S=[(R \times C 3 \times C 4)]$

Em que:

$\mathrm{S}=$ estimativa de geração total de RCC municipal $(\mathrm{kg} / \mathrm{d})$.

$R=$ valor da Equação $1(\mathrm{~kg} / \mathrm{d})$.

C3 = coeficiente de correção 3, obtido pela razão entre o total de resíduos gerados no município de Várzea Grande de novas construções e o total de resíduos gerados nas obras do município de novas construções com áreas menores que $12.000 \mathrm{~m}^{2}$, de condomínios horizontais, da zona rural, das reformas, ampliações, demolições e revitalizações e 
aquelas em situação paralisada e finalizada (adimensional).

C4 = coeficiente de correção 4 , obtido pela razão entre o total de resíduos gerados no município de Várzea Grande pelo setor de habitação e de resíduos gerados pelos demais setores (lazer, educação, saúde, entre outros), com exceção das obras de mobilidade urbana e transporte na malha viária terrestre (adimensional).

$P=[(S / U) \times D 1]$

Em que:

$\mathrm{P}$ = geração de RCC municipal de Cuiabá ou Várzea Grande em equivalente populacional (kg/hab.ano).

$\mathrm{S}=$ valor da Equação 3 ou $4(\mathrm{~kg} / \mathrm{d})$, se Cuiabá ou Várzea Grande, respectivamente.

$U$ = população urbana municipal de Cuiabá ou Várzea Grande (hab.).

D1 = dias de efetivo exercício e execução de obras em um ano nos dois municípios (d).

\subsection{Critérios de avaliação adotados para qualificar a gestão de RCC nos canteiros de obras e prefeituras}

Resumidamente, para aferir a gestão de RCC, em termos administrativos, técnicos e operacionais, nos canteiros de obras públicas e privadas e prefeituras, primeiramente, integraram-se os atributos qualitativos e quantitativos anteriormente descritos separadamente (conforme descrito e elencado no Anexo A); em seguida, eles foram contabilizados e somados, comparando com as exigências legais e critérios técnicos (padrões de referência), exclusivamente, da Resolução CONAMA n 307/2002 e das NBRs 15112 a 15116. Por fim, atribuiu-se qualificação à gestão de RCC eficaz ou ineficaz.

A atribuição negativa aos atributos dos questionários (elencados no Anexo A) ocorreu quando seu somatório resultou em negativo e quando não aten- diam aos requisitos técnico-legais da Resolução CONAMA n 307/2002 e NBRs 15112 a 15116, havendo, consequentemente, gestão de RCC ineficaz. Já a atribuição positiva deu-se quando o somatório resultou em positivo e quando atendiam aos mesmos requisitos técnico-legais, havendo, consequentemente, gestão de RCC eficaz.

\section{RESULTADOS}

\subsection{Gestão de RCC nos canteiros de obras de Cuiabá}

Com relação às visitas técnicas in loco e levantamentos nos 15 canteiros de obras, sendo dez públicas e cinco privadas, de Cuiabá, obtidos pelo histórico e média aritmética simples de informações junto aos canteiros durante um ano, a partir do início das obras, no estágio de terraplenagem até o estágio de revestimento externo, com valores absolutos de obras, áreas, caçambas estacionárias, geração de RCC, custo com disposição final de RCC e porcentagem de custo de disposição final de RCC, expressos, respectivamente, em unidades, $\mathrm{m}^{2}$, unidades, $\mathrm{kg} / \mathrm{m}^{2}$, valores absolutos e porcentagem, à luz da estatística descritiva, com o intuito de subsidiar os cálculos estimativos de RCC, são demonstrados nas Equações 6 e 7.

$R=[(T \times N \times G) / H]$

Dados de entrada:

$\mathrm{T}=12.530,64 \mathrm{~m}^{2}$

$\mathrm{N}=60$ unidades

$\mathrm{G}=90 \mathrm{~kg} / \mathrm{m}^{2}$

$H=520$ dias

Resposta: $R=130.850 \mathrm{~kg} / \mathrm{dia}$ ou 109,04 m²/dia.

$V=(R \times 0,2)$

Dados de entrada: 


\section{R: $130.850 \mathrm{~kg} / \mathrm{dia}$}

Resposta: $V=26.170 \mathrm{~kg} / \mathrm{dia}$ ou $21,81 \mathrm{~m}^{3} / \mathrm{dia}$.

Doravante, apresentam-se as avaliações qualitativas dos canteiros de obras públicas e particulares de Cuiabá, baseadas nos dados dos quesitos e respostas do questionário (Anexo $A$ ), de forma resumida, consensual e majoritária entre as 15 unidades construtivas investigadas, com atribuição positiva (+) ou negativa (-), explanação dos motivos e justificativas por quesito, somatório e porcentagem positiva (+) ou negativa (-), atribuição satisfatória ou insatisfatória, qualificação de gestão de RCC eficaz ou ineficaz e conclusão ao final dos quesitos.

Somatório e porcentagem dos atributos (quesitos dos questionários): oito atributos negativos ( $8 / 9=$ $88,8 \%)$ contra um atributo positivo $(1 / 9=11,2 \%)$.

Atribuição, baseada nos dados dos quesitos e respostas do questionário: insatisfatória.

Qualificação da gestão de RCC, baseada nos dados dos quesitos e respostas do questionário: ineficaz.

Conclusão: diante dos resultados apresentados, dos dados dos quesitos e respostas do questionário, dos indicadores de avaliação adotados e da metodologia empregada, as referidas obras não exercem a gestão ambiental plena e integrada de RCC, não cumprem nem atendem às recomendações técnico-legais da Resolução CONAMA n 307/2002.

\subsection{Gestão de RCC nos canteiros de obras de Várzea Grande}

Com relação às visitas técnicas in loco e levantamentos nos cinco canteiros de obras, sendo quatro públicas e uma privada, de Várzea Grande, obtidos pelo histórico e média aritmética simples de informações junto aos canteiros durante um ano, a partir do início das obras, no estágio de terraplenagem até o estágio de revestimento externo, com valores absolutos de obras, áreas, caçambas estacionárias, geração superficial de RCC, custo com disposição final de RCC e porcentagem de custo de disposição final de RCC, expressos, respectivamente, em unidades, $\mathrm{m}^{2}$, unidades, $\mathrm{kg} / \mathrm{m}^{2}$, valores absolutos e porcentagem, à luz da estatística descritiva, com o intuito de subsidiar os cálculos estimativos de RCC, são demonstrados nas Equações 8 e 9.

$\mathrm{R}=[(\mathrm{T} \times \mathrm{N} \times \mathrm{G}) / \mathrm{H}]$

Dados de entrada:

$\mathrm{T}=12.299,19 \mathrm{~m}^{2}$

$\mathrm{N}=40$ unidades

$\mathrm{G}=80 \mathrm{~kg} / \mathrm{m}^{2}$

$\mathrm{H}=520$ dias

Resposta: $R=72.770 \mathrm{~kg} / \mathrm{dia}$ ou $60,64 \mathrm{~m}^{3} / \mathrm{dia}$.

$V=(R \times 0,2)$

Dados de entrada:

R: $72.770 \mathrm{~kg} / \mathrm{dia}$

Resposta: $V=14.550 \mathrm{~kg} / \mathrm{dia}$ ou $12,13 \mathrm{~m}^{3} / \mathrm{dia}$.

Doravante, apresentam-se as avaliações qualitativas dos canteiros de obras públicas e particulares de Várzea Grande, baseadas nos dados dos quesitos e respostas do questionário (Anexo A), de forma resumida, consensual e majoritária entre as cinco unidades construtivas investigadas, com atribuição positiva (+) ou negativa (-), explanação dos motivos e justificativas por quesito, somatório e porcentagem positiva (+) ou negativa (-), atribuição satisfatória ou insatisfatória, qualificação de gestão de RCC eficaz ou ineficaz e conclusão ao final dos quesitos.

Somatório e porcentagem dos atributos (quesitos dos questionários): oito atributos negativos (8/9 = $88,8 \%)$ contra um atributo positivo $(1 / 9=11,2 \%)$.

Atribuição, baseada nos dados dos quesitos e respostas do questionário: insatisfatória.

Qualificação da gestão de RCC, baseada nos dados dos quesitos e respostas do questionário: ineficaz. 
Conclusão: diante dos resultados apresentados, dos dados dos quesitos e respostas do questionário, dos indicadores de avaliação adotados e da metodologia empregada, as referidas obras não exercem a gestão ambiental plena e integrada de RCC, não cumprem nem atendem às recomendações técnico-legais da Resolução CONAMA n'307/2002.

\subsection{Gestão de RCC das prefeituras de Cuiabá e Várzea Grande}

Atribuição, baseada nos dados dos quesitos e respostas do questionário: insatisfatória.

Qualificação da gestão de RCC, baseada nos dados dos quesitos e respostas do questionário: ineficaz.

Conclusão: diante dos resultados apresentados, dos dados dos quesitos e respostas do questionário, dos indicadores de avaliação adotados e da metodologia empregada, as referidas prefeituras não exercem a gestão ambiental plena e integrada de RCC, não cumprem nem atendem às recomendações técnico-legais da Resolução CONAMA $n^{\circ}$ 307/2002 (não geração de resíduos e, secundariamente, redução, reutilização, reciclagem, tratamento dos resíduos sólidos e disposição final ambientalmente adequada dos RCC universalizada) e NBRs 15112 a 15116 (ponto de entrega voluntária, triagem, disposição final, isolamento de áreas para recebimento, aproveitamento e agregados e controle de qualidade voltados aos RCC).

\subsection{Gestão de RCC comparativa entre Cuiabá e Várzea Grande}

As avaliações quantitativas comparativas dos valores estimados de geração total de RCC por dia, geração per capita de RCC e demais informações da gestão de RCC entre os dois municípios matogrossenses, durante o período de junho de 2012 a junho de 2013, a partir das Equações 1, 2, 3, 4, 5, são resumidas, evidenciadas e exemplificadas nas Figuras 1 a 4 .

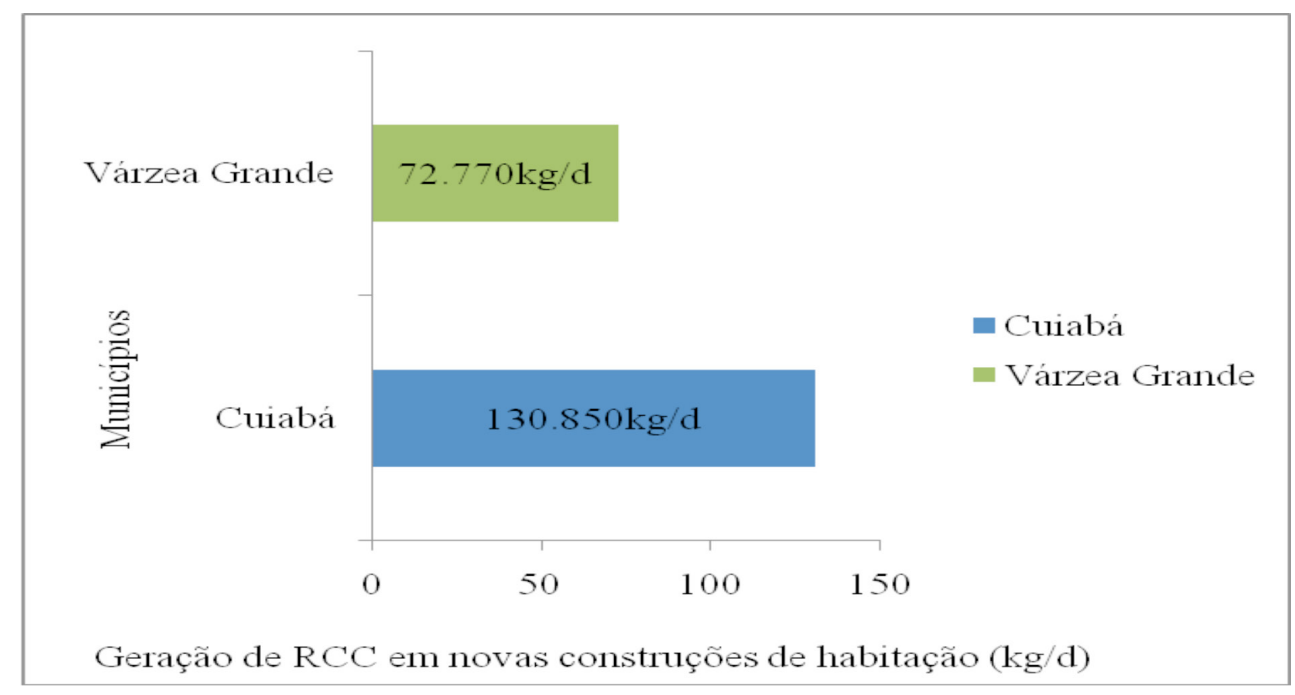

Figura 1 - Comparação da geração de RCC de novas construções em andamento com área superior a 12.000 m²$^{2}$ em Cuiabá e Várzea Grande, no período de junho de 2012 a junho de 2013. 


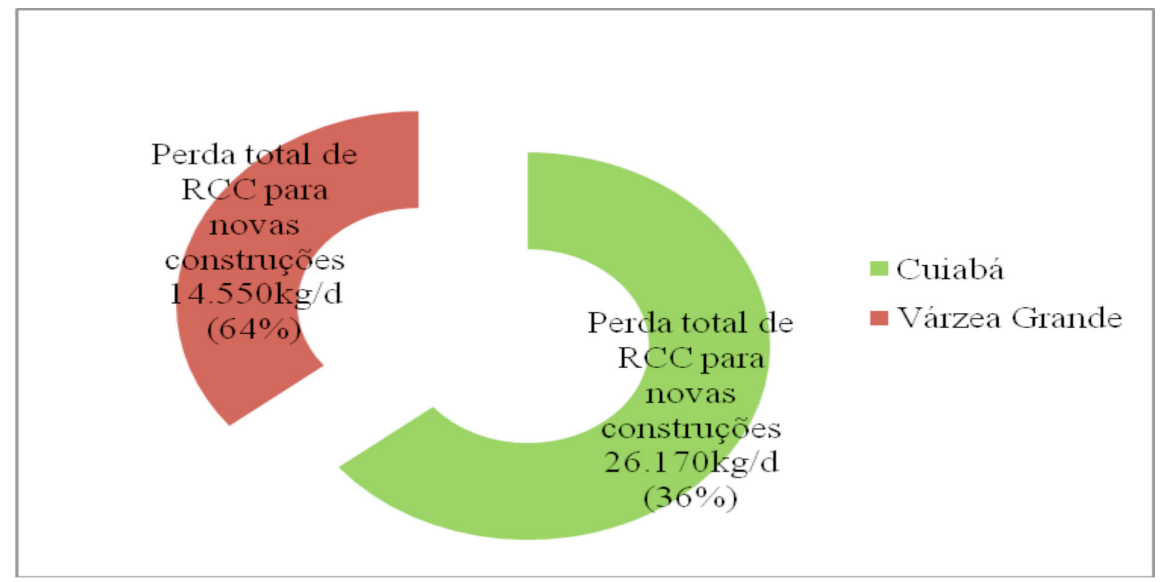

Figura 2 - Comparação da perda de materiais por quebra ou avarias intracanteiros de novas construções em andamento com área superior a $12.000 \mathrm{~m}^{2}$, em Cuiabá e Várzea Grande, no período de junho de 2012 a junho de 2013.

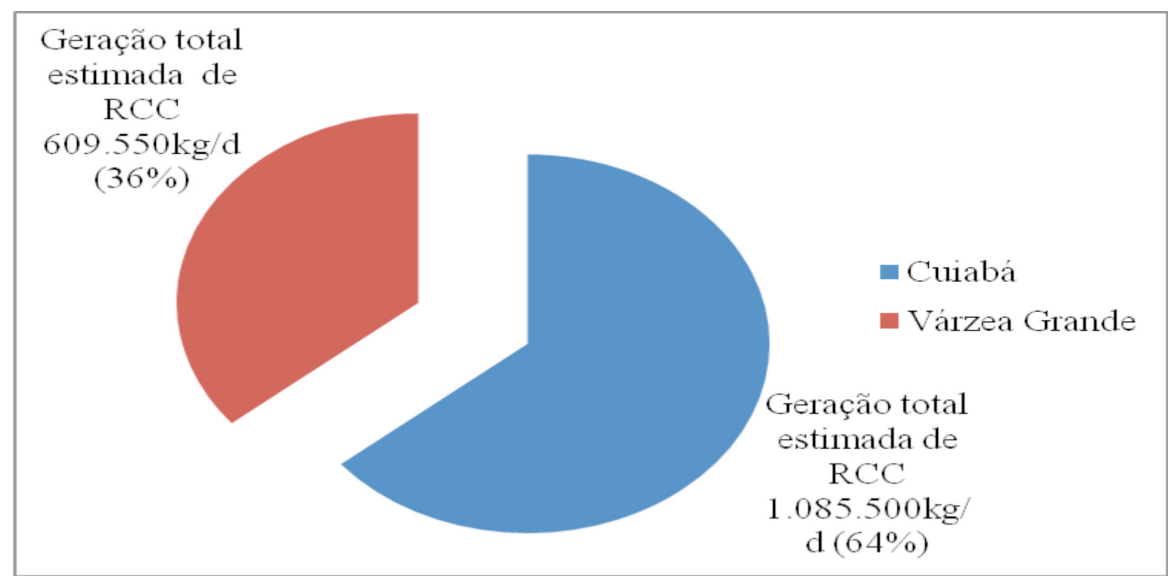

Figura 3 - Comparação da geração total de RCC, em Cuiabá e Várzea Grande, no período de junho de 2012 a junho de 2013.

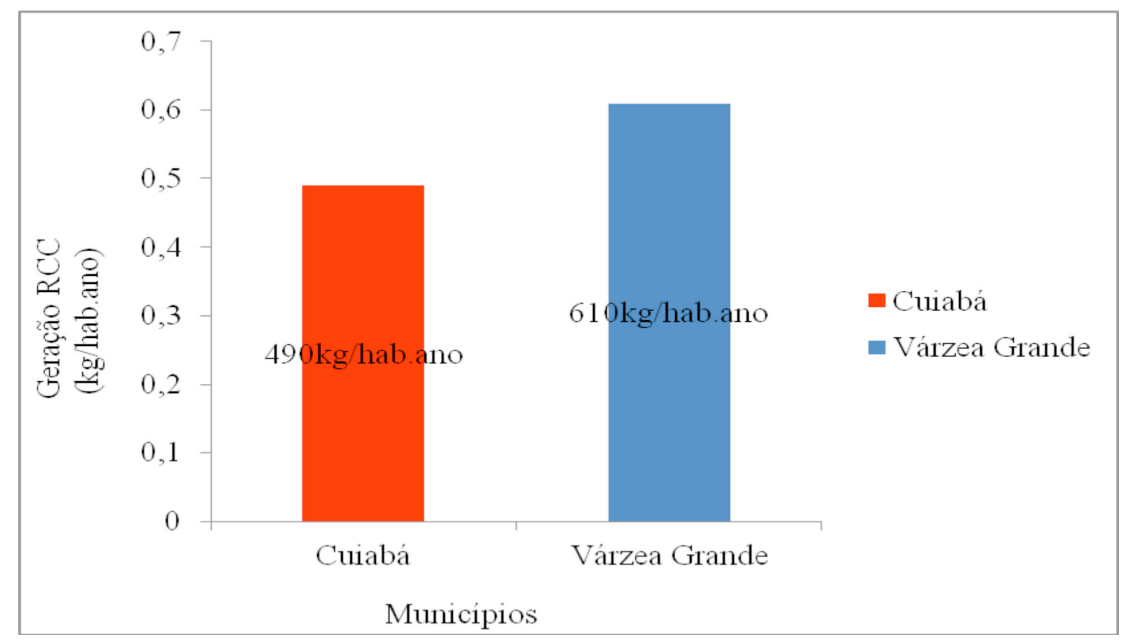

Figura 4 - Comparação da geração de RCC em equivalente populacional, em Cuiabá e Várzea Grande, no período de junho de 2012 a junho de 2013. 


\section{DISCUSSÃO}

Das Figuras 1 a 4 , inferem-se as seguintes discussões, deduções, extrapolações pertinentes e constatações:

- As obras de habitação têm maior amplitude, alcance social, acesso às classes sociais, financiamentos de bancos, facilidade e menos burocracia administrativa para aquisição entre os cidadãos brasileiros, em contexto local, regional e nacional. Por isso, representam parcela significativa na geração total de RCC dos municípios investigados.

- A disposição final irregular/informal advém dos problemas no sistema de gestão ambiental de RCC de obras públicas e privadas e das municipalidades. Por esse motivo, Cuiabá possui apenas $20 \%$ de atendimento ambientalmente adequado nesse quesito e Várzea Grande, 0\%. Em outras palavras, Cuiabá tem 868.400 kg de RCC (80\%) não encaminhados à Área de Transbordo, Triagem e Reciclagem (ATTR) Eco Ambiental e Várzea Grande tem $609.500 \mathrm{~kg} /$ dia de RCC sem destinação legal, formal ou regular.

- As obras de habitação com padrão construtivo convencional e tradicional decorrem da maior difusão do mercado imobiliário, resistência à mudança, falta de apoio e integração entre fabricantes e instituições de ensino e pesquisas científicas, competição mercadológica, preço, custo, benefício, inexistência de programas de redução, controle de perdas, deficiência de projetos básicos e executivos e não profissionalização dos profissionais atuantes no ramo da construção civil. Assim sendo, os resíduos das classes A e IIB são mais gerados e encontrados nos canteiros de obras, em relação às demais classes de RCC, conforme Resolução CONAMA nº 307/2002 e NBR 10004.

- A geração total de RCC teve valor e índice percentual maiores na capital mato-grossense do que em Várzea Grande, devido a diferenças significativas no contingente da população, Produto Interno Bruto (PIB), área territorial, importância no cenário estadual, poderio econômico, maior investimento em recursos humanos e financeiros, localidade, logística e organização legal, administrativa, técnica, operacional e institucional.

- O município de Cuiabá apresentou geração total de RCC e geração de RCC em novas construções maiores do que Várzea Grande: 1.085 .500 kg/dia contra $609.500 \mathrm{~kg} / \mathrm{dia}$, ou seja, $64 \%$ contra $36 \%$. Consequentemente, teve maior valor de RCC exclusivo das novas construções em andamento pesquisadas - $130.850 \mathrm{~kg} /$ dia contra $72.770 \mathrm{~kg} /$ dia -, bem como de suas respectivas perdas por quebras ou avarias de materiais intracanteiros de obras $-26.170 \mathrm{~kg} /$ dia contra $14.550 \mathrm{~kg} / \mathrm{dia}$. 0 valor de geração total de RCC de Cuiabá é compatível com as realidades locais e outras cidades paulistas de porte e natureza semelhantes (Ribeirão Preto e Santo André), em razão do número de obras civis construídas no referido período.

- O município de Várzea Grande apresentou maior valor de geração de RCC em equivalente populacional do que Cuiabá ( 610 kg/hab.ano contra 490 $\mathrm{kg} /$ hab.ano), mesmo tendo menor população e menor número de obras civis construídas, no referido período de estudo. Esse valor ainda é próximo da média nacional (500 kg/hab.ano) e está dentro da faixa nacional (230 a $760 \mathrm{~kg} / \mathrm{hab} . a n o$ ), além de ser compatível com as realidades locais e outras cidades paulistas de porte e natureza semelhantes (São José do Rio Preto e Piracicaba). As possíveis causas para essa situação são: menor contingente populacional (quanto menor o denominador, maior o quociente), fiscalização insuficiente, baixo nível de conscientização ambiental da sociedade local, ausência de locais, opções e alternativas para disposição final de RCC, existência de passivos ambientais e litígios judiciais com o Ministério Público Estadual de Mato Grosso (MPE-MT), nível de participação e envolvimento social na questão ambiental pela sociedade civil organizada completamente incipiente e problemas gravíssimos com insatisfatória organização 
legal, administrativa, técnica, operacional e institucional, bem como no sistema de gestão e gerenciamento ambiental de RCC.

A geração de RCC calculada nas obras investigadas - $80 \mathrm{~kg} / \mathrm{m}^{2}$ em Várzea Grande e $90 \mathrm{~kg} / \mathrm{m}^{2}$ em Cuiabá - apresentou valor próximo das novas obras em andamento, em cenário nacional (97,25 $\mathrm{kg} / \mathrm{m}^{2}$ ), conforme Silva (2007), devido às condições favoráveis de planejamento preliminar durante a execução das obras.

O referido valor de geração superficial de RCC oriunda das novas construções em andamento do setor de habitação residencial também tende a ser compatível com as edificações do tipo comercial e industrial, mas diferente das obras de reforma, ampliação, revitalização e demolição, em razão das diferenças nos critérios iniciais dos projetos básicos e exigências legais e contratuais com os agentes públicos fiscalizadores e financiadores.

Salienta-se, ainda, que a cobertura dos serviços públicos de água, resíduos sólidos, esgoto e águas pluviais nos referidos municípios é baixa - menos de $40 \%$ (IBGE, 2008). Ambos os municípios não cumprem e não atendem plenamente aos dispositivos das Leis $n^{\circ} 11.445 / 2007$ e 12.305/2010. Além disso, não possuem mapeamento dos locais de disposição irregular de RCC e as penalidades ou sanções administrativas de reparação de danos ambientais, em geral, não ocorrem na prática, permitindo generalizar a impunidade, injustiça, lentidão, cobertura e atendimento de fiscalização incipiente, inércia da sociedade e prefeituras e ausência de consciência ecológica, ambiental e cidadã dos munícipes, que ainda imperam como um todo, guardadas as devidas proporções.

Cabe também ressaltar, após visitas técnicas à Eco Ambiental, que na prática a referida ATTR de Cuiabá é uma Área de Triagem e Transbordo (ATT), pois não está realizando o beneficiamento e reciclagem de resíduos, conforme projeto inicial previsto.
Importa lembrar que a responsabilidade do gerenciamento de RCC é compartilhada por todos os geradores, transportadores, receptores, recicladores e beneficiadores, desde a geração até a disposição final, conforme Resolução CONAMA $n^{\circ} 307 / 2002$ e Lei $n^{\circ} 12.305 / 2010$, ou seja, a sociedade e prefeituras não podem se eximir dessa competência, atribuição, prerrogativa intransferível, obrigação e dever com o meio ambiente.

Destaca-se, ainda, a preocupação com a prefeitura de Várzea Grande, visto que, até o presente momento, não há controle e amparo legal, técnico, operacional e institucional da gestão de RCC. Essa situação permanece sub judice, desde 2010, com termo de ajustamento de conduta assinado entre a referida prefeitura e o MPE-MT, sob pena de incorrer em improbidade administrativa e descumprimento das leis ambientais. Não obstante tudo isso, Várzea Grande ainda possui deficits habitacionais quantitativos, planos de habitação e diretores participativos ainda não implementados (Leis Complementares n 3.112/2007 e $n^{\circ}$ 3.319/2009), urbanização desorganizada com ocupações mistas (territórios devolutos, áreas ociosas, espaços vazios ou desocupados, residenciais, comerciais e industriais), infraestruturas incipientes, estratificação social, diferenças e discrepâncias intermunicipais com Cuiabá, o que indiretamente acentua e afeta negativamente sua gestão de RCC.

Nesse contexto, ainda impera a externalização dos impactos ambientais negativos, tais como: comprometimento do tráfego de pedestres e veículos, atração de outros tipos de resíduo, poluição atmosférica, poluição visual, degradação do sistema natural, prejuízos sociais e desvalorização da área de entorno, multiplicação de vetores e doenças, danos ao patrimônio público, comprometimento da drenagem urbana, assoreamento dos córregos e poluição sonora, que acometem os locais irregulares de disposição final de RCC existentes, 
predominantemente localizados nas regiões periféricas, nos limites dos perímetros urbanos, nas margens de rodovias e nas áreas de preservação ambiental e de preservação permanente dos dois municípios. Assim, a melhor opção ainda é buscar o caminho da conscientização ecológica, com responsabilidade objetiva; participação e controle social de todos os atores envolvidos; implantação de políticas, planos e programas com conceitos de sustentabilidade ambiental; revisão dos conceitos e modelos construtivos e tecnológicos na indústria da construção civil, matriz econômica, fluxos e cadeias produtivas; redução, recuperação, reaproveitamento, reciclagem e reúso de RCC; cumprimento das exigências legais e técnicas já existentes sobre a temática; e priorização de projetos executivos integrados, racionais, exequíveis, viáveis e que respeitem as condições e realidades locais.

\section{CONCLUSÃO}

\subsection{Considerações}

No período de estudo, a maior geração de RCC ocorreu no município de Cuiabá, com 1.085.500 $\mathrm{kg}$ por dia e $490 \mathrm{~kg}$ por habitante ano (resultados compatíveis com as cidades de Ribeirão Preto e Santo André, no estado de São Paulo), enquanto Várzea Grande gerou 609.500 kg por dia e $610 \mathrm{~kg}$ por habitante ano (resultados compatíveis com as cidades de São José do Rio Preto e Piracicaba, no estado de São Paulo), no estágio de alvenaria, fundação, superestrutura e revestimento, em detrimento da terraplenagem, acabamento e manutenção ( $90 \%$ contra $10 \%$, respectivamente), ou seja, $9 / 10$ da classe $A$, contra $1 / 10$ das classes $B, C$ e D, de acordo com a Resolução CONAMA no $307 / 2002$ e suas alterações.

O município mais estruturado, organizado e institucionalizado em termos de capacitação, qualificação e habilitação na gestão de RCC foi a capital mato-grossense, bem como suas respectivas obras públicas e privadas.
Ambos os municípios, incluindo seus canteiros de obras públicas e privadas do setor de habitação, não realizam gestão ambiental plena de RCC, não cumprem nem atendem integralmente às recomendações e exigências legais e normalizações técnicas da Resolução CONAMA n 307/2002 e NBRs 15112 a 15116, diante dos indicadores de avaliação levantados, com existência de mais aspectos e critérios de gestão de RCC negativos do que positivos.

As estimativas de geração de entulhos de obras para novas construções em andamento no setor de habitação, de grandes volumes, foram compatíveis às realidades locais, considerando a metodologia empregada, no período de junho de 2012 a junho de 2013, totalizando $203.620 \mathrm{~kg} / \mathrm{dia}$, ou seja, 130.850 kg/dia em Cuiabá e 72.770 kg/dia em Várzea Grande.

A implantação do PGRCC, da gestão de RCC e das alternativas construtivas ecológicas ou ambientalmente mais sustentáveis nos canteiros de obras públicas e privadas ainda não é uma atitude voluntária em Cuiabá e Várzea Grande, ou seja, é iniciativa paliativa para cumprir exigências dos órgãos oficiais competentes, evitar multas e litígios com a justiça e veiculações pejorativas na mídia, apesar de ser capaz de contribuir na minimização dos impactos ambientais negativos, quando aplicáveis, guardadas as devidas proporções.

\subsection{Recomendações}

Exigir das instituições financeiras critérios mais rigorosos nos financiamentos e empréstimos bancários às construtoras executivas, adotando iniciativas e conceitos de sustentabilidade ambiental nas construções do setor de habitação de interesse social.

Qualificar periodicamente a fiscalização dos serviços públicos de limpeza urbana das municipalidades, para aperfeiçoar a orientação aos geradores, transportadores e receptores de resíduos. 
Integrar todos os projetos executivos de construção civil do setor de habitação, a gestão e o gerenciamento de RCC dos municípios e obras públicas e privadas.

Realizar controle de quantificação de resíduos e perdas de materiais por estágio nas obras e, na medida do possível, inserir conceitos de habitações funcionais e planejadas do built to suit (construção sob encomenda).

Substituir e associar em maior escala, gradativamente, mais materiais alternativos nos modelos tradicionais construtivos das obras, com menor impacto ambiental, quando a tecnologia disponível for viável e aplicável, tais como: estruturas pré-moldadas e metálicas, madeira e materiais recicláveis.

Aperfeiçoar o layout dos canteiros de obras públicas e privadas, no que tange ao armazenamento de materiais, estocagem, bem como sua organização, de acordo com o plano de armazenagem, gerenciamento, controle de perdas, gestão estratégica e procedimentos de expedição programada, rápida e eficiente (just in time).

Estabelecer critérios de fiscalização e aplicação de penalidades para obras que infringirem a Lei $n^{\circ}$ 12.305/2010 e a Resolução CONAMA n 307/2002, sendo esse um critério obrigatório para obtenção de financiamentos e alvarás de interesse.

\section{REFERÊNCIAS}

ASSOCIAÇÃO BRASILEIRA DE NORMAS TÉCNICAS (ABNT). Resíduos sólidos - classificação: NBR 10.004, ABNT, 2004, 71 p.

ASSOCIAÇÃO BRASILEIRA DE NORMAS TÉCNICAS (ABNT). Agregados reciclados de resíduos sólidos da construção civil - Utilização em pavimentação e preparo de concreto sem função estrutural - Requisitos: NBR 15.116, ABNT, 2004, 12 p.

ASSOCIAÇÃO BRASILEIRA DE NORMAS TÉCNICAS (ABNT). Resíduos sólidos da construção civil e resíduos inertes - Aterros Diretrizes para projeto, implantação e operação: NBR 15.113, ABNT, 2004, 12 p.

ASSOCIAÇÃO BRASILEIRA DE NORMAS TÉCNICAS (ABNT). Resíduos da construção civil e resíduos volumosos - Áreas de transbordo e triagem - Diretrizes para projeto, implantação e operação: NBR 15.112, ABNT, 2004, 7 p.

ASSOCIAÇÃO BRASILEIRA DE RESÍDUOS ESPECIAIS E DE EMPRESAS DE LIMPEZA PÚBLICA (ABRELPE). Panorama de resíduos sólidos. Brasília: ABRELPE, 2012.

ANDRADE, A.P.M.M., Otimização da gestão de resíduos da construção e demolição em obras de grande dimensão. 2011. 112p. Dissertação (Mestrado em Engenharia do Ambiente). Universidade Católica Portuguesa, Lisboa.

ÂNGULO, S.C. Variabilidade de agregados graúdos de resíduos de construção e demolição reciclados. 2000. 115p. Dissertação (Mestrado em Engenharia Civil). Escola Politécnica, Universidade de São Paulo, São Paulo.

BOTTA, A. M. Gerenciamento de resíduos da construção civil em Uberaba-MG.

CAIXA ECONÔMICA FEDERAL. Espaço habitação. Notícias online, 2013. Disponível em <http://www.caixa.gov.br/destaque_habitacao.html>. Acesso em: 13/06/2013.

CÂMARA BRASILEIRA DA INDÚSTRIA DA CONSTRUÇÃO (CBIC). Guia de boas práticas de sustentabilidade na indústria da construção civil e desenvolvimento em construções sustentáveis. Brasília: CBIC, 2013.

FREITAS, M. I. Os Resíduos da construção civil no município de Araraquara. 2009. 86p. Dissertação (Mestrado em Desenvolvimento Regional e Meio Ambiente). Centro Universitário de Araraquara, Araraquara.

GONZALEZ, M.A.S.; RAMIRES, M.V.V., Análise da gestão de resíduos gerados dentro dos canteiros de obras.

INSTITUTO BRASILEIRO DE GEOGRAFIA E ESTATÍSTICA (IBGE). Pesquisa nacional de amostragem por domicílio - Contagem. Rio de Janeiro: IBGE, 2013.

INSTITUTO BRASILEIRO DE GEOGRAFIA E ESTATÍSTICA (IBGE). Censo demográfico de 2010. Rio de Janeiro: IBGE, 2010.

INSTITUTO BRASILEIRO DE GEOGRAFIA E ESTATÍSTICA (IBGE). Pesquisa Nacional de amostragem por domicílio de 2009. Rio de Janeiro: IBGE, 2009.

INSTITUTO BRASILEIRO DE GEOGRAFIA E ESTATÍSTICA (IBGE). Pesquisa nacional de saneamento básico 2008. Rio de Janeiro: IBGE, 2010.

INSTITUTO BRASILEIRO DE GEOGRAFIA E ESTATÍSTICA (IBGE). Perfil dos municípios brasileiros. Notícias online, 2012. Disponível em: <http://www.ibge.gov.br>. Acesso em: 02/05/2012.

INOJOSA, F.C.P., Gestão de resíduos da construção: a Resolução Conama 307/2002 no Distrito Federal. 2010. 225p. Dissertação (Mestrado em Desenvolvimento sustentável). Universidade de Brasília, Brasília. 
INSTITUTO DE PESQUISA ECONÔMICA APLICADA (IPEA). Panorama de resíduos da construção civil. Brasília: IPEA, 2012.

JOHN, V. M., Desenvolvimento sustentável, construção civil, reciclagem e trabalho multidisciplinar. Notícias online, 2007. Disponível em: <http://www.reciclagem.pcc.usp.br/destaque_resíduos da construção civil.html> Acesso em: 03/03/2012.

MINISTÉRIO DO MEIO AMBIENTE (MMA). Manual de implantação de gestão de resíduos da construção civil. Brasília: MMA, 2010.

MARQQUES NETO, Gestão dos resíduos de construção e demolição no Brasil. São Carlos-SP. Editora RIMA, v.1, n.1, p.3-148, 2005.

PINTO, T.P. Resíduos da construção no Distrito Federal: diagnóstico geral. Brasília, Caixa Econômica Federal, 2008.

PINTO, T. P.; GONZÁLES, J. L. R. Manual de orientação de manejo e gestão dos resíduos da construção civil: como implementar um sistema de manejo e gestão nos municípios. 2005. 194p. Brasília: Caixa Econômica Federal, v.1, n.1.

PINTO, T.P. Metodologia para a gestão diferenciada de resíduos sólidos da construção urbana. 1999. 189p. Tese (Doutorado em Engenharia Civil) - Escola Politécnica, Universidade de São Paulo, São Paulo.

Pontifícia Universidade Católica do Rio Grande do Sul, Gestão diferenciada de resíduos da construção civil uma abordagem ambiental. Porto Alegre: EDIPUCRS, v.1, p.1-164, 2009.

PUCCI, R.B. Logística de resíduos da construção civil atendendo à Resolução CONAMA 307/2002. 2006. 137p. Dissertação (Mestrado em Engenharia Civil). Escola Politécnica, Universidade de São Paulo, São Paulo.

PREFEITURA MUNICIPAL DE CUIABÁ (PMC). Relatório técnico de acompanhamento de gerenciamento de resíduos da construção civil. Cuiabá: PMC, 2012.

RESOLUCAO CONAMA No 307, de 05 de Julho de 2002. Estabelece diretrizes, critérios e procedimentos para a gestão dos resíduos da construção civil. Brasília, DOU n 136 de 17/07/2002.

RIBEIRO, J. R. Proposta de um manual para gestão dos resíduos da construção civil em cidades brasileiras. 2009. 211p. Dissertação (Mestrado em Engenharia de Produção). Universidade Estadual de São Paulo, Bauru.

SECRETARIA ESTADUAL DAS CIDADES DE MATO GROSSO (SECID -MT). Plano diretor integrado participativo da região metropolitana do Vale do Rio Cuiabá. Cuiabá: SECID, 2012.

SILVA, V.A.; FERNANDES, A.L.T. Cenário do gerenciamento dos resíduos da construção e demolição (RCD) em Uberaba-MG.

SILVA, A.F.F. Gerenciamento de resíduos da construção civil de acordo com a Resolução Conama 307/02 - Estudo de caso para conjunto de obras de pequeno porte. 2007. 102p. Dissertação
(Mestrado em Saneamento, Meio Ambiente e Recursos Hídricos). Universidade Federal de Minas Gerais, Belo Horizonte.

SINDICATO DAS EMPRESAS DE COMPRA, VENDA, LOCAÇÃO E ADMINISTRAÇÃO DE IMÓVEIS RESIDENCIAIS E COMERCIAIS DE MATO GROSSO. Habitação. Notícias online, 2013. Disponível em:<http:www.secovimt.com.br/2013/notícias.html.> Acesso em: 18/10/2013.

SINDICATO DA INDÚSTRIA DA CONSTRUÇÃO CIVIL DE MATO GROSSO. Gestão de resíduos da construção civil e de demolição. Notícias online, 2012. Disponível em: <http:www.sindusconmt.com.br/envios/2013/eventos/resíduos/folheto_sinduscon_2012.pdf.> Acesso em: 01/06/2012.

SINDICATO DA INDÚSTRIA DA CONSTRUÇÃO CIVIL DO CEARÁ (SINDUSCON-CE). Manual de resíduos sólidos da construção civil. Pernambuco: SINDUSCON-CE, 2011.

SOUZA, U. E. L. Como reduzir perdas nos canteiros: Manual de gestão do consumo de materiais na construção civil. São Paulo: Pini, 2005.

\section{ANEXO A - QUESTIONÁRIOS COM OS ATRIBUTOS PARA AVALIAÇÃO DA GESTÃO DE RCC}

Questionário A - Atributos para avaliação da gestão de RCC nos canteiros de obras públicas e privadas

1. Qual é a área total construída da obra $\left(\mathrm{m}^{2}\right)$ ?

2. Qual é o número total de trabalhadores diretos da obra?

3. Qual é o prazo da obra, de acordo com o cronograma físico-executivo?

4. Qual é o prazo médio por estágio da obra?

5. Quais são a quantidade estimada de RCC durante os estágios da obra e seu somatório $(\mathrm{kg})$ ?

6. Quais são as classes e tipologias de RCC mais geradas?

7. Qual é o estágio da obra com maior contribuição na geração de RCC?

8. A obra possui licença ambiental?

9. A obra possui algum tipo de certificação ambiental por auditorias internas ou externas? 
10. Quais são a qualificação e a formação profissional dos trabalhadores da obra?

11. A obra possui algum tipo de material ecológico aplicado?

12. A obra recebeu algum tipo de fiscalização dos órgãos oficiais durante a execução?

13. A obra possui contabilizado o custo médio com coleta, transporte e destinação final de RCC?

14. Qual é aa distância da obra em relação ao destino final dos RCC?

15. A obra possui controle de quantidade de perdas de materiais de construção civil aplicado?

16. A obra possui algum tipo de passivo ambiental, no que tange aos RCC, com os órgãos oficiais?

\section{Questionário B - Atributos para avaliação da gestão de RCC nas prefeituras de Cuiabá e Várzea Grande}

1. Quais são os principais bairros com obras de construção civil na área de habitação?

2. O município tem algum tipo de matéria-prima, materiais e insumos empregados nas obras de construção civil?

3. O município possui construtoras da construção civil especializadas em execução de obras no setor de habitação?

4. Qual é a tipologia de transporte de materiais, insumos e matérias-primas no município empregada na construção civil?

5. O município possui política ambiental voltada aos resíduos sólidos, em especial, aos RCC?

6. O município recebe fiscalização para obtenção de licenças ambientais e alvarás das suas próprias obras?
7. O município possui algum tipo de litígio judicial, devido a passivos ambientais decorrentes de RCC?

8. Quais são os locais de ATTR e assemelhados dentro do município?

9. Qual é a estrutura organizacional e institucional, bem como seu quadro técnico profissional, referente à gestão de RCC do município?

10. Existem recursos financeiros suficientes, programas de governo, verbas e investimentos na área ambiental, em relação aos resíduos sólidos, em especial?

11. Dentro do orçamento municipal, qual é a percentagem (\%) e valor ( $\mathrm{R} \$$ ) destinado à área ambiental, em especial à gestão de RCC?

12. O município possui terceirização no serviço e sistema de manejo de RCC e limpeza pública? Esta possui auditoria ou fiscalização?

13. Qual é a quantidade estimada de RCC $(\mathrm{kg})$ no município?

14. A prefeitura possui cadastro de empresas de caçambas estacionárias e transportadores de RCC? Qual é sua quantidade?

15. A prefeitura possui taxas exclusivas previstas no orçamento municipal para o setor da limpeza urbana e gestão de RCC?

16. A prefeitura tem conhecimento e informação dos principais locais de disposição irregular de RCC?

17. A prefeitura tem o conhecimento e informação exata do número de novas construções em andamento de junho de 2012 a junho de 2013 na área de habitação? 